\title{
A emergência da cura pela palavra na medicina mental do século XIX
}

\author{
Rafaela Teixeira Zorzanelli
}

Este artigo analisa algumas das condições de possibilidade da emergência da terapia pela palavra no rol de terapêuticas médicas no fim do século XIX. A hipótese é de que o processo de construção do psiquismo, como objeto médico, está relacionado à emergência de categorias de doença referidas a sintomas sem explicação anatômica, como foi o caso da neurastenia, da histeria e da psicastenia, que contribuíram para tornar insuficiente a referência à organicidade como causa de doenças mentais e para a criação de um novo gênero de clínica centrado na fala.

Palavras-chave: Terapia pela palavra, medicina mental, categorias médicas 
(...) As palavras são também a ferramenta essencial do tratamento anímico.

O leigo por certo achará difícil compreender que as perturbações patológicas do corpo e da alma possam ser eliminadas através de "meras" palavras. Achará que

lhe estão pedindo para acreditar em bruxarias. E não estará tão errado assim: as palavras de nossa fala cotidiana não passam de magia atenuada.

Sigmund Freud

Nosso campo de investigação se refere à construção, na medicina norte-americana e européia do fim do século XIX, de uma noção particular de morbidade mental, por meio da qual o psíquico passa a ser entendido como uma dimensão não redutível ao biológico e dotada de intencionalidade, trazendo como consequência a admissão da talking cure (cura pela palavra) ${ }^{1}$ na medicina mental daquela época. Taylor (1907) acena para essa transformação quando comenta sobre as mudanças que ganhavam lugar na atitude médica na primeira década do século XX, demonstrando uma abertura dentro da medicina mainstream para as terapêuticas que levavam em conta a vida mental. Nosso objetivo é compreender algumas das condições de possibilidade para que se pudesse chegar, por exemplo, nos idos do século XX, a uma asserção célebre como a de Lacan (1977) de que à psicanálise caberia des-

1. Talking cure é a expressão inicialmente utilizada por Bertha Pappenhein, paciente do médico vienense Joseph Breuer, para se referir àquele tipo de tratamento a que estava sendo por ele submetida. Esse termo tornou-se um lugar comum para a referência a terapêuticas baseadas na fala do paciente. Detalhes sobre essa ideia são encontrados em Freud e Breuer (1893/1980). 
fazer pela palavra o que foi feito por ela. Como a palavra, a ideia, a representação passaram a ser pensadas como geradoras de sofrimento e de patologia, no seio da medicina mental do fim do século XIX?

O foco na segunda metade do século XIX e início do século XX é de particular importância, já que esse momento, segundo Rosenberg (1989), foi crucial na articulação entre hipóteses etiológicas e pressuposições morais, e entre emoções e seus resultados aparentemente patológicos. Tal período é considerado um momento de expansão das categorias de doença e do desenvolvimento tardio do conceito de neurose, marcado principalmente pela emergência da mistura entre moléstias emocionais, estados alterados de humor e padrões de desvio de comportamento, legitimados como doenças.

À ideia da emergência da cura pela palavra se pode objetar que várias formas de terapia mental existiam antes dessa, tais como o magnetismo, a hipnose, a escrita automática - isso, se não nos detivermos nas suas variações religiosas, como as curas xamânicas e espíritas. ${ }^{2}$ No entanto, essa modalidade de terapia no seio da medicina do fim do século XIX revela uma síntese particular e uma estrutura organizada, que transforma o que outrora aparecia disforme em um território secularizado, transmissível e legítimo dentro de um campo aliado ao método científico, que é a medicina.

Queremos chegar à ideia de que a busca de território para o psíquico, na construção das patologias, e a possibilidade de pensá-lo como objeto estava sendo gestada na medicina e que esse processo foi, em grande parte, construído pela criação de categorias médicas para abordá-lo e tratá-lo - sobretudo, as categorias usadas para as dores sem lesão, febres intermitentes, paralisias, contraturas e fadiga - para as quais não se encontravam correlatos físicos, alterações nos tecidos e órgãos, ou lesões post mortem no cérebro. ${ }^{3} \mathrm{O}$ histérico, o neurastênico, o psicastênico são personagens diretamente envolvidos na construção da história de uma noção particular de morbidade psíquica e do nascimento da talking cure.

Conforme Abbott (1998), dois grupos contribuíram de forma determinante para a constituição do campo de especialistas em tratar o mal-estar individual: os

2. A respeito das diferentes modalidades de cura da psique e do lugar da talking cure entre elas, confira Jackson (1999) e Falzeder (2000).

3. Conforme Hodgkiss (2000), a dor sem lesão colocou uma ameaça ao modelo anatomoclínico, principalmente quando somada a sintomas difusos como a fadiga, a perda de memória, a insônia e outros. Foucault (2004) também chama a atenção para o problema das febres essenciais e das neuroses como entidades que, no fim do século XVIII e início do século XIX, colocavam em xeque o raciocínio anatomopatológico segundo o qual a essência da doença está relacionada à sua sede. 
clérigos e os neurologistas. Sobre esse último nos interessa particularmente detalhar, já que o campo de ação da neurologia seria herdado, no correr do século $\mathrm{XX}$, pelos psicanalistas e psicoterapeutas, ${ }^{4}$ dentre outras profissões. A seara dos problemas pessoais ganhou contornos muito particulares na virada do século XIX para o XX, definindo um novo modo de abordagem por meio de propostas terapêuticas e teóricas trazidas pelo saber psicanalítico, não por acaso, emergente das mãos de Sigmund Freud, um neurologista.

Poder-se-ia objetar ainda que o objeto psíquico já estava presente desde o início na medicina, especificamente na psiquiatria, não sendo correto circunscrevê-lo ao fim desse mesmo século. De fato, mesmo antes da ocupação pela neurologia do terreno dos problemas pessoais, a psiquiatria circunscrevia sua atividade ao cuidado com a insanidade e com o manejo das instituições de asilamento que, desde o início do século XIX, desenrolava-se sob uma forma psiquista, até ser suplantada pelo organicismo da neurologia alemã e anglo-saxã, na década de 1850. No entanto, o que Pinel (1800) qualificava de moral, para se referir às paixões e aos comportamentos humanos, não possuía características suficientes para que lhe suponhamos uma autonomia em relação aos processos fisiológicos. O moral era muito mais um resultado inseparável dos processos físicos, o que justificava, por exemplo, terapias de ação corporal (banhos, massagens), com supostos efeitos sob a conduta do indivíduo. ${ }^{5}$

4. Segundo Marx (1992), o paciente neurótico com o qual a psicanálise vai se confrontar em seus primórdios era o público típico da prática da neurologia, passando, depois da emergência da psicanálise, a ser também o dos psiquiatras de orientação dinâmica.

5. A abordagem da loucura advogada por Phillipe Pinel modelou nossa compreensão de sua terapêutica sugerindo o uso de tratamento moral em substituição ao tratamento restritivo. $\mathrm{O}$ início do século XIX estabeleceu, assim, a idéia de que a insanidade podia ser alvo de intervenção terapêutica, conforme debateu Swain (1994). Mas a virada para o século XX trouxe consigo a ideia de que à doença psíquica seria necessário oferecer um tratamento de mesma natureza, abrindo espaço para o tratamento pela fala, o que é um passo diferente dos que se havia dado até então dentro do saber médico. Com isso, pressupõe-se que o psíquico seria um agente causal de pleno direito, não redutível às lesões cerebrais. A noção de psiquismo (e de sua morbidade), emergente no fim do século XIX, e o movimento da terapia pela fala, que lhe acompanha, não é uma mera repetição da tendência psiquista pineliana do início daquele século. O fato de que Pinel reconheça a insuficiência dos métodos anatomofisiológicos na busca da sede da loucura não lhe faz um descrente na existência dela. A terapia moral dos asilos e as terapêuticas psicológicas do fim do século XIX certamente partilham certos pressupostos, como o impacto dos aspectos ambientais e experienciais sobre os indivíduos e suas doenças, e a própria ideia de que o psiquismo pode ser alvo de intervenção terapêutica. Mas, o objeto moral de que a insanidade trata não pode ser subsumido à noção de intencionalidade psíquica emergente no fim do século XIX. 
De acordo com o que sustentamos, a possibilidade de pensar o psiquismo como objeto médico foi construída a partir da presença clínica de sintomas não explicados por alterações orgânicas, cuja abordagem inicial foi a formulação do conceito de neurose ainda no século XVIII, a partir dos trabalhos do médico britânico William Cullen [1710-1790]. A nosso ver, essa forçosa inserção ocorreu, lentamente, pela utilização, no âmbito da biomedicina, de categorias e conceitos indecidíveis entre o moral e o orgânico, que permitiram pensar os sintomas sem etiologia detectável. A ausência de uma explicação anatômica ou fisiológica para sintomas e síndromes, como previsto pelo protocolo médico da época, impulsionou a pressuposição da ação de uma entidade não redutível ao orgânico, dotada de intencionalidade, capaz de determinar sintomas físicos e comportamentais, e, por consequência, passível de intervenção terapêutica de natureza psicológica. Essa entidade seria, então, o psiquismo, cujo caminho mais fácil de acesso foram suas manifestações mórbidas e seu funcionamento irregular.

Mas a partir de quais categorias médicas, prioritariamente, foram dados os primeiros passos para a construção da ideia de que o psiquismo é capaz de produzir doenças, podendo ser alvo de terapêuticas não somáticas. Destacaremos três: a neurastenia, criada em solo norte-americano pelo neurologista George Beard (1839-1883); a histeria, que no fim do século XIX estava associada ao neurologista francês Jean Martin Charcot (1825-1893) e, já no início do século XX, a psicastenia, debatida pelo neurologista francês Pierre Janet (1859-1947). Passaremos a uma breve apresentação de cada uma delas.

A criação da neurastenia como categoria médica é atribuída a George Beard, em meados de 1869. A condição era caracterizada por enfraquecimento da força dos nervos com graus diferenciados de severidade, desde a perda discreta até a prostração profunda e generalizada. Os sintomas apresentados eram extremamente variados, incluindo perturbações gástricas, neurológicas, geniturinárias. No cerne da sintomatologia estava a exaustão nervosa, caracterizada pela fadiga injustificada, tanto física quanto mental. A doença foi pensada a partir de Beard (1880, 1881) como uma mistura de predisposição constitucional - nervos fracos - e excessos despendidos em uma sociedade que requisitava o gasto do estoque de energia nervosa, sendo uma consequência do estilo de vida norte-americano e do ritmo extremo do desenvolvimento daquele país, que gerava a american nervousness. Apesar de também assinalar o papel da hereditariedade, Beard (1880) não deixa dúvida quanto à etiologia da condição: a causa da nervosidade americana é a civilização e suas mazelas. ${ }^{6}$

6. Para um panorama sobre o tema, confira Rosenberg (1962). 
Já no caso da histeria, destaca-se a importância de Charcot para a sustentação dessa categoria, no fim do século XIX. Para o autor, a histeria era uma doença funcional do sistema nervoso que trazia como consequência sintomas sensoriais, dores crônicas, hemianestesia, cefaléias, contraturas e crises motoras. Seu olhar trouxe, como afirma Freud (1893) dignidade, autenticidade e objetividade aos fenômenos histéricos, pois elevou o status da histeria ao de qualquer outra afecção nervosa com lesão material, embora nela essa alteração material fosse dinâmica ou funcional. Charcot (1888) analisou casos de paralisia histerotraumática, e por meio deles detecta diferenças entre as lesões corticais e as lesões da histeria. As primeiras possuem focos limitados e se distribuem ao acaso sobre as regiões motoras e sensitivas do córtex, sendo distintas e distantes umas das outras. As lesões dinâmicas da histeria, além de difusas, afetariam simultânea e sistematicamente as regiões motoras e sensitivas, fisiologicamente implicadas na execução do movimento de uma dada articulação. ${ }^{7}$

A psicastenia, por sua vez, foi um diagnóstico cunhado pelo neurologista francês Pierre Janet [1859-1947], nos dois volumes da obra "Les obsessions et la psychasténie" (1903). Juntamente com a histeria e a neurastenia, a psicastenia compõe o quadro mais amplo de condições neuróticas do fim do século XIX. Os sintomas da psicastenia diziam respeito à presença de ideias fixas, obsessões e impulsos, manias mentais, dúvidas, tiques, sensações de despersonalização. Toda essa riqueza sintomatológica apontaria para uma perturbação da função de realidade (fonction du réel), que alteraria o modo de apreensão da realidade, tanto no campo da percepção quanto no da ação. É em razão da psicolepsia, isto é, da queda da tensão psicológica, que as funções mais complexas desaparecem na psicastenia. É digno de nota que Janet (1903), ainda que reconhecesse a importância da hereditariedade e de fatores orgânicos, atribuísse grande importância à dinâmica da energia psíquica. É também por isso que seus trabalhos são considerados contribuições decisivas para a constituição de um sistema de psiquiatria dinâmica e para o desenvolvimento da psicoterapia como método de tratamento de transtornos mentais (Ellenberguer, 1970; Pitman, 1984).

Por se tratar, nos três casos, de morbidades cujos sintomas se apresentavam sem substrato orgânico identificável, essas entidades médicas são emblemáticas do modo como a medicina da virada do século XIX para o XX lidava com doenças cujos sinais e sintomas não encontravam correspondência na estrutura anatômica. Novos horizontes históricos se abriram por meio dessas categorias,

7. Para um estudo histórico mais detalhado da histeria como categoria médica, recomendamos os trabalhos de Trillat (1991) e Micale (1989a, 1989b, 1990, 1993). 
ao anunciarem uma crise da razão médica baseada na correspondência entre lesão e sintoma. Elas contribuem não somente para a criação posterior de uma noção particular de morbidade psíquica relacionado ao campo da psicanálise, mas, sobretudo, para um gênero novo de clínica médica centrado sobre as condutas, os ditos, crenças e desejos inferidos.

Contribuíram, ainda, para que a dimensão orgânica das patologias se tornasse insuficiente como explicação exclusiva das causas de doenças mentais e de suas manifestações sintomáticas. Certamente isso não seria inteiramente operado por Beard, Charcot ou Janet, mas essas entidades clínicas ofereceriam condições de possibilidade para o processo de legitimização da intencionalidade psíquica, da autonomia do psiquismo como objeto médico, da formação do conceito de inconsciente freudiano, e do exercício da terapêutica pela palavra no seio da medicina mental novecentista, sobretudo em continente europeu.

A neurastenia é considerada o ponto de partida de uma atenção dada, na história da medicina mental, aos fatores sociais como agentes provocadores de doenças (Ehrenberg, 1998). Tal categoria teria tornado insuficiente a referência à hereditariedade como causa e, com base na noção de lesão funcional, houve um deslocamento de um modelo da doença como lesão para o de doença como reação patológica a um evento, sem necessariamente a presença de uma lesão estrutural. A degenerescência, apesar de presente nas hipóteses etiológicas, não era uma explicação suficiente e, por isso, o fator sociocultural estava no primeiro plano da etiologia (Zorzanelli, 2009). Para Bynum (1986), essas categorias ajudam ainda a definir mais claramente as diferenças entre o campo da neurologia e da psiquiatria ${ }^{8}$ e ao mesmo tempo oferecem condições para o nascimento da psiquiatria dinâmica e da psicanálise, e, ao longo do século XX, das psicoterapias - assentadas, cada uma a seu modo, no papel curativo da palavra.

Com isso, segundo Ehrenberg (2004), o início do século XX fundou, a partir da clínica, uma separação entre o sujeito da neurologia, cujo sintoma está em algum ponto de seu sistema nervoso a sua revelia - e o sujeito falante da psicopatologia, da psiquiatria, e da psicanálise, cujo sintoma lhe é inteiramente singular.

8. Falar em psiquiatria ou em neurologia nesse período que estamos tratando exige alguns cuidados - ainda que alguns teóricos não se acanhem em utilizá-los, como Bynum (1986). Isso porque os limites entre esses campos ainda eram instáveis e pouco definidos, tendo em comum o terreno do tratamento das doenças nervosas. Até meados do século XIX, não havia uma diferenciação entre neurologia e psiquiatria, tampouco entre doenças do cérebro e da mente, já que a ideia sustentada era de que os processos mentais eram, invariavelmente, o resultado de funções cerebrais subjacentes. 
Em consonância, Bynum (1986) afirma que, por volta de 1800, os neurologistas tratavam as doenças funcionais, enquanto os psiquiatras confiavam na base orgânica subjacente às doenças, principalmente da insanidade. Já no fim do século, os psiquiatras passam a aceitar a realidade das doenças mentais, e os neurologistas tomaram como objeto as doenças prioritariamente orgânicas. A essa altura, o psíquico já se colocava como uma entidade considerada portadora de leis próprias, com ação sobre o físico, e como objeto de escrutínio de saberes e práticas específicas, como foi o caso da psicanálise freudiana.

\section{Referências}

Аввотт, A. The System of Professions: An Essay on the Division of Expert Labor. Chicago: The University of Chicago Press, 1988.

BEARD, G. A practical treatise on nervous exhaustion (neurasthenia). New York: William Wood, 1880. Sons, 1881. . American Nervousness. Its causes and consequences. New York: Putnan

Bynum, W.F. The Nervous Patient in Eighteenth - and Nineteenth-Century Britain: the Psychiatric Origins of British Neurology. In: Bynum, W.F. et al. (Org.). The Anatomy of Madness, v. 1, 1986.

Charcot, J.M. Septième Leçon. In: Leçons du mardi à la Salpêtriére. Paris: Lecrosniew \& Babe, 1888. Tomo 1, p. 111-34.

Ellenberg, H. Pierre Janet and Psychological Analysis. In: The discovery of the unconscious. New York: Basic Books, 1970. p. 331-417.

Ehrenberg, A. Le sujét cerebral. Esprit, p. 130-155, nov. 2004. . La fatigue d'être soi. Depréssion et societé. Paris: Odile Jacob, 1998.

FALZEDER, E. Profession - psychoanalyst: a hystorical view. Psychoanalysis and History, v. 2, n. 1, p. 37-60, feb. 2000.

Foucault, M. O nascimento da clínica. Rio de Janeiro: Forense Universitária, 2004.

Freud, S.; Breuer, J. (1893). Estudos sobre a histeria. Edição Standard Brasileira das Obras Psicológicas Completas de Sigmund Freud. Rio de Janeiro: Imago, 1980. V. II.

Hodgkiss, A. From lesion to metaphor: chronic pain in British, French and German medical writings, 1800-1914. Amsterdam: Rodopi B.V, 2000. 
JACKson, S. Care of the Psyche. A history of psychological healing. New Haven \& London: Yale University Press, 1999.

Janet, P.; Raymond, F. Les obséssions et la psychasténie. Paris: Alcan, 1903. V. 1.

LACAN, J. Seminaire XXV. Le moment de conclure. Aula de 15.11.77. Disponível em: http://www.ecole-lacanienne.net/stenos/seminaireXXV/1977.11.15.pdf. Acesso em: maio de 2008.

Marx, O.M. What is the history of psychiatry? History of Psychiatry, v. 11, n. 3, p. 279-292, set.1992.

Micale, M. Hysteria and its historiography. A review of past and present writings (I). History of Science, n. 27, p. 223-261, set.1989a.

. Hysteria and its historiography: a review of past and present writings (II). History of Science, n. 27, p. 319-351, set.1989b.

. Hysteria and its historiography: the future perspective. History of Psychiatry, n. 1, p. 33-124, mar.1990.

. On the "disappearance" of hysteria. A study in the clinical deconstruction of a diagnosis. Isis, v. 84, n. 3, p. 496-552, set.1993.

Pinel, P. (1800). Tratado médico-filosófico sobre a Alienação Mental ou a Mania. Tradução de Joice A. Galli. Porto Alegre: Ed. da UFGRS, 2007.

Pitman, R.K. Janet's obsessions and psychasthenia: a synopsis. Psychiatric Quarterly, v. 56. n. 4, dez.1984.

Rosenberg, C. The place of George M. Beard in nineteenth-century psychiatry. Bulletin of the history of medicine, n. 36, p. 245-259, mai-jun.1962.

. Body and mind in nineteenth-century medicine: some clinical origins of the neurosis construct. Bulletin of the History of medicine, n. 63, p. 185-197, jun.1989. SwaIn, G. De Kant a Hegel: deux époques de la folie. In: Dialogues avec l'insensé. Paris: Gallimard, 1994. p. 1-28.

TAYLOR, E.W. The attitude of the medical profession toward the psychotherapeutic movement. Boston Medical and Surgical Journal, n. 157, p. 843-9, jun.1907.

Trillat, E. História da histeria. São Paulo: Escuta, 1991.

ZorZANELl, R.T. A fadiga e seus transtornos: condições de possibilidade, ascensão e queda da neurastenia novecentista. História, Ciências, Saúde - Manguinhos, Rio de Janeiro, v. 16, n. 3, p. 605-620, jul-set.2009. 
(The emergence of the talking cure in 19-century mental medicine)

This paper analyses the conditions present for the emergence of the talking cure as one among other medical therapies in the late $19^{\text {th }}$ century. The hypothesis is that the construction of the psychism as a medical object is related to the emergence of medical categories for symptoms that seem to have no anatomical basis, such as neurasthenia, hysteria and psychosthenia. These categories helped show that purely organic explanations were insufficient to explain many symptoms. They therefore contributed to the establishment up a new style of clinical treatment based on speech.

Key words: Talking cure, mental medicine, medical categories

(La naissance de la thérapie par la parole au 19e siècle)

Cet article analyse quelques conditions qui ont favorisées le surgissement de la thérapie par la parole parmi d'autres thérapeutiques médicales à la fin du XIX siècle. Notre hypothèse défend que le processus de construction du psychisme comme objet de la médicine va de pair avec le surgissement des catégories des maladies dont les symptômes n'ont pas de cause anatomique, comme la neurasthénie, l'hystérie et la psychasthénie. Celles-ci ont contribué à la conclusion que les explications organiques sont insuffisantes, ainsi qu'à la création d'un nouveau genre de clinique centrée sur la parole.

Mots clés: Thérapie par le parole, médicine mentale, catégories médicales

(La emergencia de la terapia por la palabra en la medicina mental del siglo XIX)

Este artículo presenta algunas condiciones que permiten tratar el psiquismo através del surgimiento de la terapia por la palabra en las terapéuticas medicas a finales del siglo XIX. La hipótesis que se defiende es la de que el proceso de construcción del psiquismo como objeto médico está relacionado con el surgimiento de categorías de enfermedades para síntomas sin explicación anatómica, como la neurastenia, la histeria y de la psicoastenia que contribuyeron para tornar insuficiente como causa la organicidad y para la creación de un nuevo genero de clínica centralizado en la palabra.

Palabras clave: Terapia por la palabra, medicina mental, categorías médicas

Citação/Citation: ZoRZanelli, R.T. A emergência da cura pela palavra na medicina mental do século XIX. Revista Latinoamericana de Psicopatologia Fundamental, São Paulo, v. 14, n. 2, p. 298-308, jun.2011.

Rev. Latinoam. Psicopat. Fund., São Paulo, v. 14, n. 2, p. 298-308, junho 2011 
Editor do artigo/Editor: Prof. Dr. Manoel Tosta Berlinck

Recebido/Received: $15.3 .2010 / 3.15 .2010$ Aceito/Accepted: $12.5 .2010 / 5.12 .2010$

Copyright: () 2009 Associação Universitária de Pesquisa em Psicopatologia Fundamental/ University Association for Research in Fundamental Psychopathology. Este é um artigo de livre acesso, que permite uso irrestrito, distribuição e reprodução em qualquer meio, desde que o autor e a fonte sejam citados/This is an open-access article, which permits unrestricted use, distribution, and reproduction in any medium, provided the original author and source are credited.

Financiamento/Funding: A autora declara não ter sido financiados ou apoiados/The authors has no support or funding to report.

Conflito de interesses/Conflict of interest: A autora declara que não há conflito de interesses/The author declares that has no conflict of interest.

\section{Rafaela Teixeira Zorzanelli}

Psicóloga formada pela Universidade Federal do Espírito Santo - UFES (Vitória, ES, Brasil); Mestre em Psicologia pela Universidade Federal Fluminense - UFF (Niterói, RJ, Brasil); Doutora em Saúde Coletiva pelo Instituto de Medicina Social da Universidade do Estado do Rio de Janeiro - UERJ (Rio de Janeiro, RJ, Brasil), Pós-doutoranda do Instituto de Medicina Social da UERJ, com apoio da Fundação de Amparo à Pesquisa do Rio de Janeiro - FAPERJ/CAPES - Coordenação de Aperfeiçoamento de Pessoal de Nível Superior.

Instituto de Medicina Social - UERJ

Rua São Francisco Xavier, 524

Pavilhão João Lyra Filho, $7^{\circ}$ andar, blocos D e E - Maracanã 20550-900 Rio de Janeiro, RJ, Brasil

Fone: (21) 2334-0504

e-mail: rtzorzanelli@yahoo.com.br 